\title{
NORMALIZATION AND VARIANT ASSESSMENT METHODS IN SELECTION OF ROAD ALIGNMENT VARIANTS - CASE STUDY
}

\author{
Wladyslaw GARDZIEJCZYK, Piotr ZABICKI \\ Bialystok University of Technology, Faculty of Civil and Environment Engineering, \\ 45E Wiejska Street, 15-351 Bialystok, Poland
}

Received 25 Sep 2015; accepted 25 Feb 2016

\begin{abstract}
The choice of the most beneficial road alignment variant is a multicriteria issue, based on transport, economic, social and environmental criteria. The criteria chosen for a multicriteria analysis can be expressed through measurable or immeasurable parameters. In order to compare and assess the variants it is necessary to normalize the criteria, which means a rescaling of their value, so that the criteria values fall into a specific range. The main aim of normalization is to assign an identical weight to each criterion in relation to other criteria. This article presents a review of the influence of criteria normalization methods and the variant assessment methods on the choice of the most beneficial road alignment variant on the example of the bypass of the town of Księżyno, which is a stretch of Regional Road 678 near Bialystok. Four variants of road alignment were compared and their ranking was created using six assessment methods. It was proven that the choices of the criteria normalization method as well as the variant assessment method both have significant influence on the result of the multicriteria analysis in the decision-making process of selecting the road alignment.
\end{abstract}

Keywords: multicriteria analysis, normalization, criteria weights, assessment, bypass, case study.

\section{Introduction}

The process of designing roads is difficult and requires taking many factors into account, which is done by using the multicriteria analysis of the suggested variants of a designed road. The multicriteria analysis is a set of algorithms used to select the most beneficial variant of road alignment, while taking into account transport, environmental, economic and social criteria weights (De Silva, Tatam 1996; Kalamaras et al. 2000; De Luca et al. 2012; Gardziejczyk, Zabicki 2014). It is based on the appropriate selection of assessment criteria and the weights assigned to them.

There are many known methods of conducting multicriteria analyses. We can distinguish methods based on the aggregation of ratings into a utility function: e.g. AHP (Saaty 1980), MAUT (Keeney, Raiffa 1976) as well as methods based on outranking relations: e.g. ELECTRE (Roy 1985), PROMETHEE (Brans, Vincke 1985). Other methods worth of mentioning are methods such as: SAW (MacCrimon 1968), TOPSIS (Hwang, Yoon 1981), VIKOR (Opricovic, Tzeng 2004), COPRAS (Zavadskas et al. 2007).

A set of specific solution variants $V=\left\{V_{i}: i=1\right.$, $2,3, \ldots, n\}$ is analysed, for which a set of criteria is assigned $K=\left\{K_{j}: j=1,2,3 \ldots, m\right\}$. These criteria are used to assess the individual variants. Each variant has its $x_{i j}$ values assigned (the value of the $V_{i}$ variant according to the $K_{j}$ criterion), thus forming the data matrix: $X=\left\{x_{i j}\right.$ : $i=1,2,3, \ldots, n ; j=1,2,3, \ldots, m\}$. Within the data matrix, the $i$-th line presents the characteristic of the ' $i$ ' variant according to individual (all) criteria, and the $j$-th column presents the individual variants according to the ' $j$ ' criterion. In table notation, the matrix has the form (1):

$$
\left[\begin{array}{ccccc}
x_{11} & \ldots & x_{1 j} & \ldots & x_{1 m} \\
\vdots & \ddots & \vdots & \ldots & \vdots \\
x_{i 1} & \ldots & x_{i j} & \ldots & x_{i m} \\
\vdots & \ldots & \vdots & \ddots & \vdots \\
x_{n 1} & \ldots & x_{n j} & \ldots & x_{n m}
\end{array}\right]
$$

The selected variant assessment criteria and their assigned point weights play a crucial role in the assessment of the variants of the designed road. The criteria used in the multicriteria analysis are expressed with measurable parameters (e.g. the criterion of 'road length' is expressed in kilometers) and immeasurable ones, describing the variants without their quantitative assessment (e.g. influence on landscape). In the multicriteria analysis we can take into account both the quantity criteria (e.g. area of forest to be cut down) and quality ones (e.g. road surface type)

Corresponding author: Piotr Zabicki

E-mail: trafficpz@o2.pl 
(Yelda, Shrestha 2003; Jakimavicus, Burinskiene 2009; Haghighat 2011). The quality criteria need to be quantified (given numeric values). In order to compare and assess the variants, it is necessary to normalize the criteria, which means a rescaling of their value, so that the criteria values fall into a specific range. The main aim of normalization is to assign an identical weight to each criterion in relation to other criteria. If the values of maximizing criteria are growing, it implies that the situation is getting better, while in the case of minimizing criteria, this means a worsening of the situation. Integration is achieved by normalization, which helps to convert all the criteria values into non -dimensional, i.e. comparable quantities.

There are many known methods of criteria normalization. Each of the mentioned normalization methods has its advantages and disadvantages, is more or less useful in the process of selecting the road alignment. However, in most cases, after normalization the criteria values are within the set of $[0 ; 1],[1 ; \sim 0]$ or [0; (Zavadskas et al. 2008; Turskis et al. 2009; Peldschus 2009). When the normalization process is finished, it is possible to determine the criteria with weights. The sum of criteria weights should equal to 1 (Eqn (2)):

$$
\sum_{j=1}^{m} \varpi_{j}=1
$$

where $\varpi_{j}-$ is the $j$-th criterion weight for the $i$-th alternative.

\section{Literature review}

The impact of various normalization methods on the decision-making process was widely discussed in many studies. A selection of comparative studies is presented below.

Barzilai and Golany (1994) stated that the number of alternatives influences the normalization process. An improperly chosen normalization method can cause the variant ranking to be inverted. Similar conclusions were obtained by Garcia-Cascales and Lamata (2012) in their analysis of the inverted ranking in the TOPSIS approach.

Szwabowski and Deszcz (2001) researched the following methods of normalization: Weitendorf's, Pattern, standardisation and norming. Basing on the calculation examples related to general construction, the authors pointed out a few meaningful facts concerning the use of these methods. The Weitendorf's and Pattern normalization methods both reduce the dimensional quantities to the interval $[0 ; 1]$, where in the case of the method by Weitendorf values of "0" are obtained. Similarly to the standardisation method, this fact is the cause for eliminating this method from the methods requiring normalized values to be greater than 0 . In order to eliminate this problem, it was suggested to introduce a value close to zero, albeit a positive one. Such action is simple, although it influences the clarity of the analysis. Additionally, the authors stress that in the case of Weitendorf's normalization method and standardisation the obtained differences between the normalized values are greater than in the case of norming and Pattern methods.

Milani et al. (2005), through the introduction of various normalization methods to the TOPSIS method, have shown that linear normalization methods do not have a significant influence on the variant ranking. At the same time, non- linear normalization can cause deviations, mainly for variants which have similar criteria values.

The method of maximum standardisation was used by Geneletti (2005) for the selection of the road corridor in northern Italy due to the linear dependency of the results.

Brauers and Zavadskas (2006) studied the use of various normalization methods for the MOORA method (Multi-Objective Optimization on the basis of Ratio Analysis). The analysis of normalization methods such as total ratio, Weitendorf ratio, Jüttler ratio, Stopp ratio, Körth ratio, Peldschus ratio for nonlinear normalization, Van Delft and Nijkamp ratio of maximum value, have proven that the best choice is vector normalization. Brauers et al. (2008) analysed various methods of criteria normalization when selecting a highway construction design with the possibility of using them in the multicriteria MOORA method.

Chakraborty and Yeh (2007) in their study based on a simulation conducted the assessment of the influence of commonly used normalization methods in the SAW method for general multicriteria issues. The results of the simulation-based study show that vector normalization and linear transformation are more appropriate than other procedures.

Zavadskas and Turskis (2008), Zavadskas et al. (2007, 2008) from the five normalization methods: vector (Van Delft and Nijkamp), linear (Weitendorf's), nonlinear (Peldschus), Jüttler's and Körth's normalization and logarithmic, used for the choice of the outer building façade, have shown that the most stable results are obtained through the logarithmic normalization method as a solution to a multicriteria decision-making problem.

Peldschus (2009) analysed linear functions (Jüttler's, Körth's, Weitendorf's) as well as non-linear ones (hyperbolic Stopp, Peldschus square and cubic, square root, logarithmic). The author points to problems, which appear in minimising of characteristic values, which twice exceed the minimum value from the variant description. Additionally, each non-linear function distorts the original problem. If maximising and minimising are both required to solve the decision-making problem, attention must be paid to avoid large differences between both cases.

Chatterjee and Chakraborty (2014) studied the influence of the criteria normalization method (Van Delft and Nijkamp, Weitendorf's, Jüttler's and Körth's, nonlinear normalization) on the choice of the variant of a flexible manufacturing system. Three multicriteria methods - PROMETHEE, TOPSIS and GRA - were used. Out of the four normalization methods, the authors preferred vector normalization. 
Celen (2014) in his study determined the effects of various normalization procedures on the decision choice in various decision-making methods (FAHP and TOPSIS) in relations to Turkish bank deposits. It was determined that the most cohesive results are obtained with vector normalization. Among the linear normalization procedures, max-min and max methods appeared as the possible alternatives to the vector normalization procedure.

Jahan and Edwards (2015) showed that when selecting materials in engineering designs, where there is a wide selection of materials of similar properties and many criteria to be fulfilled, an appropriate normalization process needs to be used. It was demonstrated that while many normalization methods appear to be only minor variants of each other, these small differences can have important consequences for the quality of decision making when selecting materials in engineering design.

The presented overview of the selected issues of criteria normalization shows a series of significant problems in the decision-making process. This article contains criteria normalization which was conducted according to eleven methods, while selecting the road alignment variant of the bypass of the town of Księżyno, which is a stretch of Regional Road 678, using six variant assessment methods.

\section{Criteria normalization methods}

Table 1 shows criteria normalization methods used to assess road alignment variants. Some of the functions are linear, some are non-linear. The method of maximum standardisation can be used to normalize both the maximising and minimising criteria.

\section{Methods of variants assessment}

Various rules are used to create a ranking variant, in order to calculate the normalized value $S^{*}$ while taking into account all of the criteria for a given variant (Zavadskas et al. 2003, 2008; Zavadskas, Turskis 2008; Turskis et al. 2009). Their short characteristic is presented below. Methods of variant assessment by Wald, Savage, Hurwicz and Laplace do not use criteria weights to establish the variant rankings. Criteria weights are taken into account in methods by Bayes and Hodges-Lehmann.

\subsection{Wald's rule (WA)}

A decision-making method according to which such a variant needs to be chosen, which has a corresponding highest value of the worst values for each variant:

$$
S^{*}=\max _{i} \min _{j} x_{i j}^{*}
$$

\subsection{Savage criterion (SA)}

A decision-making criterion according to which one has to select the variant, which would minimise the losses in relations to the optimal variant. The relative loss needs to be calculated for each variant, creating a matrix from the elements being the difference between maximum loss and the loss for each variant. Maximum relative losses for each variant form a vector, whose minimal element points to the variant which is minimising the potential loss:

$$
S^{*}=\min _{i} \max _{j} c_{i j}^{*}
$$

where $c_{i j}^{*}=\max _{i} x_{i j}^{*}$.

\subsection{Hurwicz's rule (HU)}

A decision- making method according to which one has to choose the variant with the highest corresponding value. It is a compromise between the optimistic and the pessimistic approach, and requires the selection of an optimism coefficient $(\lambda)$ within the range of $[0,1]$, after which the value of $\lambda$-row's maximum $+(1-\lambda) \cdot$ row's minimum needs to be calculated:

$$
S^{*}=\lambda \max _{j} x_{i j}^{*}+(1-\lambda) \min _{j} x_{i j}^{*} .
$$

The value $\lambda=1$ is the most pessimistic solution (Wald's rule). With a value of $\lambda=0$ only the maximum (highest risk) values are taken into account.

\subsection{Laplace's rule (LA)}

A decision-making method according to which one has to choose the variant with the highest expected value, with the assumption that all states of nature are equally probable:

$$
S^{*}=\max _{i}\left(\frac{1}{n} \sum_{i=1}^{n} x_{i j}^{*}\right)
$$

\subsection{Bayes's rule (BA)}

According to this rule the variant ranking is obtained by multiplying the normalized values by their weights. The variant, whose sum of normalized values with reference to weights is the highest, is the most beneficial solution:

$$
S^{*}=\max _{i}\left(\sum_{j=1}^{m} \varpi_{j} x_{i j}^{*}\right) \cap \sum_{j=1}^{m} \varpi_{j}=1 .
$$

\subsection{Hodges-Lehmann rule (HL)}

According to this rule, the confidence in the knowledge of the probabilities of the opponent's strategies can be expressed by the $\lambda$ parameter:

$$
S^{*}=\max _{i}\left[\lambda \sum_{j=1}^{n} \varpi_{j} x_{i j}^{*}+(1-\lambda) \min _{j} x_{i j}^{*}\right],
$$

where $\lambda=0$ (no confidence) gives the solution according to Wald's rule, while $\lambda=1$ (great confidence) gives the solution according to Bayes's rule. 
Table 1. Criteria normalization methods

\begin{tabular}{|c|c|c|}
\hline Normalization method & Maximising normalization & Minimising normalization \\
\hline Van Delft and Nijkamp normalization & $x_{i j}^{*}=\frac{x_{i j}}{\sqrt{\sum_{i=1}^{n} x_{i j}^{2}}}$ & $x_{i j}^{*}=1-\frac{x_{i j}}{\sqrt{\sum_{i=1}^{n} x_{i j}^{2}}}$ \\
\hline Weitendorf's normalization & $x_{i j}^{*}=\frac{x_{i j}-x_{j}^{-}}{x_{j}^{+}-x_{j}^{-}}$ & $x_{i j}^{*}=\frac{x_{j}^{+}-x_{i j}}{x_{j}^{+}-x_{j}^{-}}$ \\
\hline Peldschus normalization & $x_{i j}^{*}=\left(x_{i j} / x_{j}^{+}\right)^{2}$ & $x_{i j}^{*}=\left(x_{j}^{-} / x_{i j}\right)^{3}$ \\
\hline Jüttler's normalization & $x_{i j}^{*}=\frac{x_{j}^{+}-x_{i j}}{x_{j}^{+}}$ & $x_{i j}^{*}=\frac{x_{j}^{-}-x_{i j}}{x_{j}^{-}}$ \\
\hline Stopp normalization & $x_{i j}^{*}=\frac{100 x_{i j}}{x_{j}^{+}}$ & $x_{i j}^{*}=\frac{100 x_{j}^{-}}{x_{i j}}$ \\
\hline Jüttler's and Körth's normalization & $x_{i j}^{*}=1-\left|\frac{x_{j}^{+}-x_{i j}}{x_{j}^{+}}\right|$ & $x_{i j}^{*}=1-\mid \frac{x_{j}^{-}-x_{i j}}{x_{j}^{-}}$ \\
\hline Logarithmic normalization & $x_{i j}^{*}=\frac{\ln \left(x_{i j}\right)}{\ln \left(\prod_{i=1}^{n} x_{i j}\right)}$ & $x_{i j}^{*}=\frac{1-\frac{\ln \left(x_{i j}\right)}{\ln \left(\prod_{i=1}^{n} x_{i j}\right)}}{n-1}$ \\
\hline Linear normalization & $x_{i j}^{*}=\frac{x_{i j}}{\sum_{i=1}^{n} x_{i j}}$ & $x_{i j}^{*}=1-\frac{x_{i j}}{\sum_{i=1}^{n} x_{i j}}$ \\
\hline Pattern normalization & $x_{i j}^{*}=\frac{x_{i j}}{\sum_{i=1}^{n} x_{i j}}$ & $x_{i j}^{*}=\frac{x_{i j}^{\prime}}{\sum_{i=1}^{n} x_{i j}^{\prime}}$ \\
\hline Standardisation & $x_{i j}^{*}=\frac{x_{i j}-\overline{x_{j}}}{\sigma_{j}}$ & $x_{i j}^{*}=(-1) \frac{x_{i j}-\overline{x_{j}}}{\sigma_{j}}$ \\
\hline Maximum standardisation & $x_{i j}^{*}=\frac{-x_{i j}}{x_{j}^{+}}+1$ & \\
\hline
\end{tabular}

The notations in Table 1 refer to:

$x_{i j}^{*} \quad-$ normalized value of the $i$-th variant according to $j$-th criterion;

$x_{i j} \quad-$ value of the $i$-th variant according to $j$-th criterion;

$x_{j}^{+}=\max _{i}\left(x_{i j}\right), x_{j}^{-}=\min _{i}\left(x_{i j}\right)$ - maximum or minimum value of the $i$-th variant according to the $j$-th criterion;

$x_{i j}^{\prime}=1 / x_{i j}$

$\overline{x_{j}} \quad$ - average value of the analysed variants according to the $j$-th criterion, $\overline{x_{j}}=\sum_{i=1}^{n} x_{i j} / n$;

$\sigma_{j} \quad$-standard deviation, $\sigma_{j}=\sqrt{\sum_{i=1}^{n}\left(x_{i j}-\overline{x_{j}}\right)^{2} / n}$. 


\section{The choice of bypass alignment variant - case study}

\subsection{Assumptions}

The review of the criteria normalization method and the variant assessment method is presented on the example of selecting the variant of bypass alignment for the town of Księżyno in the stretch of the Regional Road 678 (Fig. 1). It is the incoming road to the city of Bialystok from the south, which makes it important for the inhabitants of nearby towns. It is a part of the national road system and connects the main cities within the districts. According to measurements performer in 2010, the average daily traffic for the regional road 678 was 17080 vehicles per day (with an average value on regional roads in the Podlaskie Voivodship being 2432 vehicles per day). The majority of vehicles were passenger cars and delivery vehicles (approx. 92\%). The remaining types of vehicles were approximately $2 \%$ (buses) and $5 \%$ (trucks with and without trailers) of traffic. The regional road 678 runs through many towns, in close proximity to housing. Terrain limitations and high - density housing make it impossible to use effective solutions for the fulfilment of the requirements relating to environment protection. In such cases, bypasses of towns are constructed, and the first step in doing this is the preparation of design documentation of such investments. At this stage, similarly to national roads, there is a problem of comparing the variants of the designed road's alignment and determining which solution is the most beneficial for the transport of people and goods, while fulfilling the requirements related to environment protection, health and safety of the inhabitants.
The analysed variants of bypass alignment are shown in Figure 1:

- variant $V 1$ - the alignment of the bypass on the north side of the town, the designed road passes mainly through forest areas, length of the bypass is $3.214 \mathrm{~km}$;

- variant $V 2$ - the alignment of the bypass on the north side of the town, the designed road runs closest to housing areas, length of the bypass is $3.00 \mathrm{~km}$;

- variant $V 3$ - the alignment of the bypass on the south side, the designed road requires the smallest number of demolitions, length of the bypass is $2.980 \mathrm{~km}$;

- variant V4 - the alignment of the bypass on the south side, the designed road is characterised by the largest tortuosity and requires the largest area of new terrain and housing terrain to be acquired, length of the bypass is $3.781 \mathrm{~km}$.

Taking into account the characteristics of the area through which the road is passing, the article purposefully selects the variants of similar length and significant diversity in collision with green areas, number of housing developments to be demolished or the length of the required noise barriers. The multicriteria analysis for the choice of the alignment of this road section was conducted basing on nineteen sub-criteria (K1-K19) assigned to criteria groups such as transport, environmental, economic and social (Table 2). The analysis used quantitative criteria. Special attention was put to the environmental and social criteria due to the frequent protests of local communities against road construction or house demolishing and resettlement. The values of the individual criteria were determined by the authors basing on their own

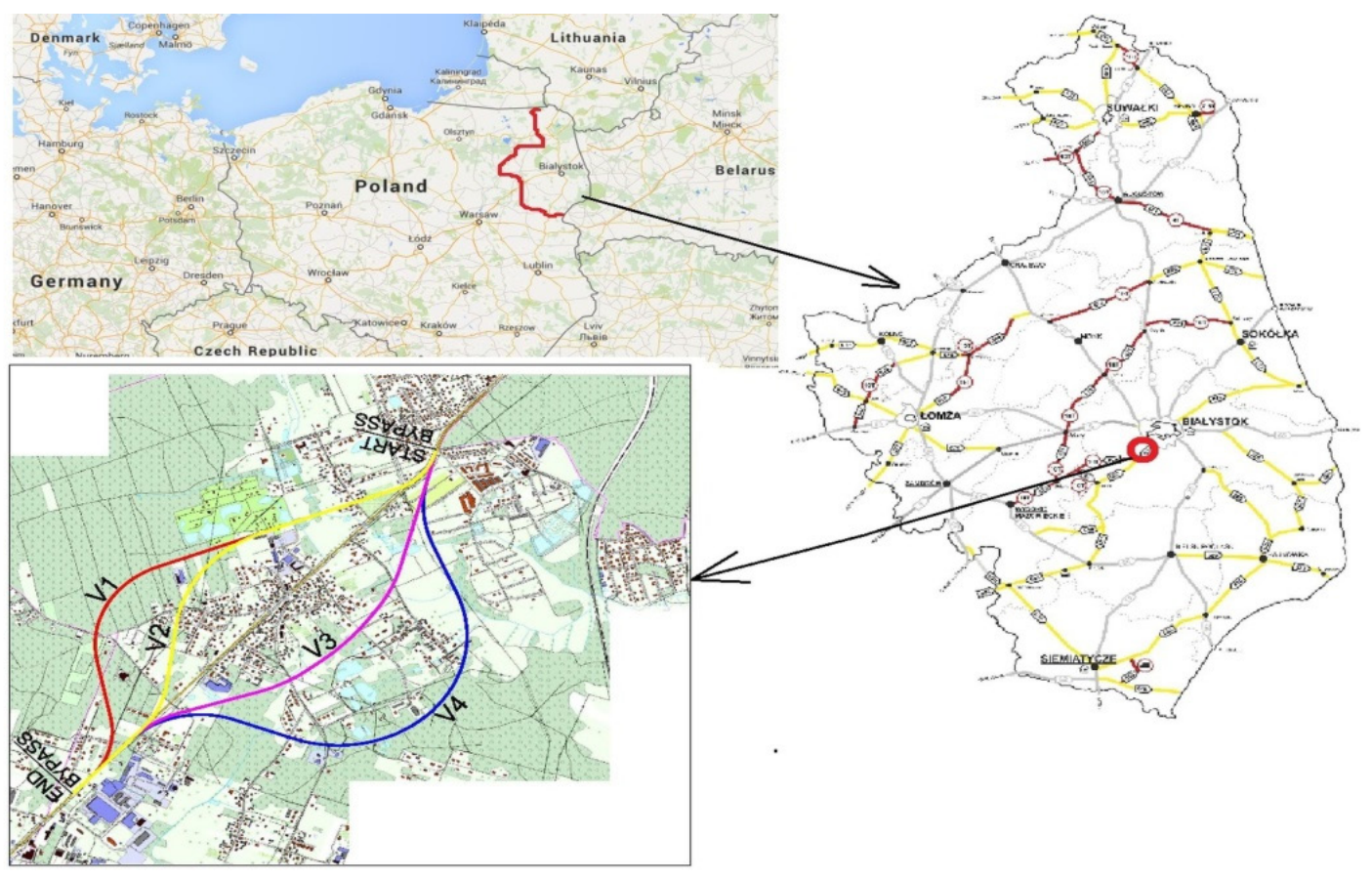

Fig. 1. The variants of bypass alignment for the town of Księżyno 
Table 2. Description of road alignment variants

\begin{tabular}{|c|c|c|c|c|c|c|}
\hline \multirow{2}{*}{ No. } & \multirow{2}{*}{ Criteria } & \multirow{2}{*}{$*$} & \multicolumn{4}{|c|}{ Variant } \\
\hline & & & $V 1$ & $V 2$ & $V 3$ & $V 4$ \\
\hline \multicolumn{7}{|c|}{ TRANSPORT } \\
\hline$K 1$ & Length of road [km] & - & 3.214 & 3.00 & 2.980 & 3.781 \\
\hline$K 2$ & Tortuosity of road $\left[{ }^{\circ} / \mathrm{km}\right]$ & - & 56.94 & 48.00 & 29.87 & 63.47 \\
\hline$K 3$ & Transport activity [veh-km/d] & + & 73842 & 68925 & 68466 & 86868 \\
\hline$K 4$ & Occupation of housing terrain $\left[\mathrm{km}^{2}\right]$ & - & 0.02 & 0.0333 & 0.011 & 0.043 \\
\hline$K 5$ & Availability - number of crossings [number] & + & 4 & 4 & 3 & 3 \\
\hline \multicolumn{7}{|c|}{ ENVIRONMENTAL } \\
\hline K6 & Occupation of new terrain $\left[\mathrm{km}^{2}\right]$ & - & 0.137 & 0.107 & 0.121 & 0.161 \\
\hline$K 7$ & Length of road through forest areas $[\mathrm{km}]$ & - & 1.6 & 0.79 & 0.58 & 1.14 \\
\hline$K 8$ & Length of collision with amphibian migratory corridors $[\mathrm{km}]$ & - & 0.2 & 0.375 & 0.875 & 0.925 \\
\hline$K 9$ & Influence on surface waters - collision with watercourses [number] & - & 3 & 3 & 4 & 6 \\
\hline$K 10$ & Collision with valuable nature areas $\left[\mathrm{km}^{2}\right]$ & - & 0.014 & 0.015 & 0.047 & 0.046 \\
\hline \multicolumn{7}{|c|}{ ECONOMIC } \\
\hline K11 & Construction cost $\left[10^{6}\right.$ EUR $]$ & - & 19.285 & 18 & 17.88 & 22.685 \\
\hline$K 12$ & $\begin{array}{l}\text { Number of engineering structures - passages for animals and } \\
\text { amphibians [number] }\end{array}$ & - & 7 & 6 & 8 & 8 \\
\hline$K 13$ & Cost of environment protection equipment $\left[10^{6} \mathrm{EUR}\right]$ & - & 0.5157 & 0.75 & 1.2025 & 0.925 \\
\hline$K 14$ & Cost of buying out terrain and buildings $\left[10^{6}\right.$ EUR $]$ & - & 0.745 & 1.2925 & 0.245 & 1.0225 \\
\hline \multicolumn{7}{|c|}{ SOCIAL } \\
\hline$K 15$ & $\begin{array}{l}\text { Number of housing buildings within a } 0.1 \mathrm{~km} \text { distance from } \\
\text { road axis [number] }\end{array}$ & - & 43 & 80 & 51 & 49 \\
\hline$K 16$ & Number of housing buildings to be demolished [number] & - & 6 & 11 & 2 & 9 \\
\hline$K 17$ & Number of agricultural buildings to be demolished [number] & - & 14 & 11 & 4 & 2 \\
\hline$K 18$ & Number of plots to be expropriated [number] & - & 115 & 143 & 137 & 147 \\
\hline$K 19$ & Length of noise barriers $[\mathrm{km}]$ & - & 2.179 & 3.217 & 4.948 & 3.828 \\
\hline
\end{tabular}

Note: * "_" minimising criteria, “+” maximising criteria.

calculations and estimations. In order to better explain the influence of the criteria normalization method on the choice of the road alignment variant, the number of criteria was limited to nineteen. The transport criteria take into account the length and the tortuosity of the road, transport activity, occupation of housing areas, availability expressed through the number of crossings. The environmental criteria take into account: occupying of new terrain, length of road passing through forest areas, length of collision with amphibians' migration corridors, influence on surface waters and collisions with valuable nature areas. The economic criteria include: the cost of road construction based on the cost of constructing one kilometer of road at a level of 6 million EUR in the case of a dual carriageway with two lanes in each direction, the number of engineering objects accommodated to the migration of amphibians and animals, cost of environmental protection devices, cost of buying out terrain and buildings. The social criteria take into account the number of housing buildings within a $0.1 \mathrm{~km}$ distance from the road's axis, amount of housing and agricultural buildings to be demolished, number of plots to be expropri- ated and the length of noise barriers. The analysis does not take into account such factors as: emission of harmful substances, soil pollution, probability of malfunction, tremors and vibrations.

\subsection{Analysis of criteria normalization methods}

Eleven criteria normalization methods were analysed. Figure 2 presents a visual representation of the obtained results for the nineteen criteria, while describing four bypass alignment variants for the town of Księżyno. The analysed methods were divided into three groups according to predetermined values.

The first group includes methods for which the criteria have the value of [0-1] (Van Delft and Nijkamp's, linear normalization, Pattern).

The second group includes these methods (Weitendorf's, Peldschus', Stopp's, maximum standardization) for which the normalized criteria have positive values with some of them having the value of 0 (maximum standardization) or 1 (Peldschus, Stopp) or both 0 and 1 (Weitendorf). 

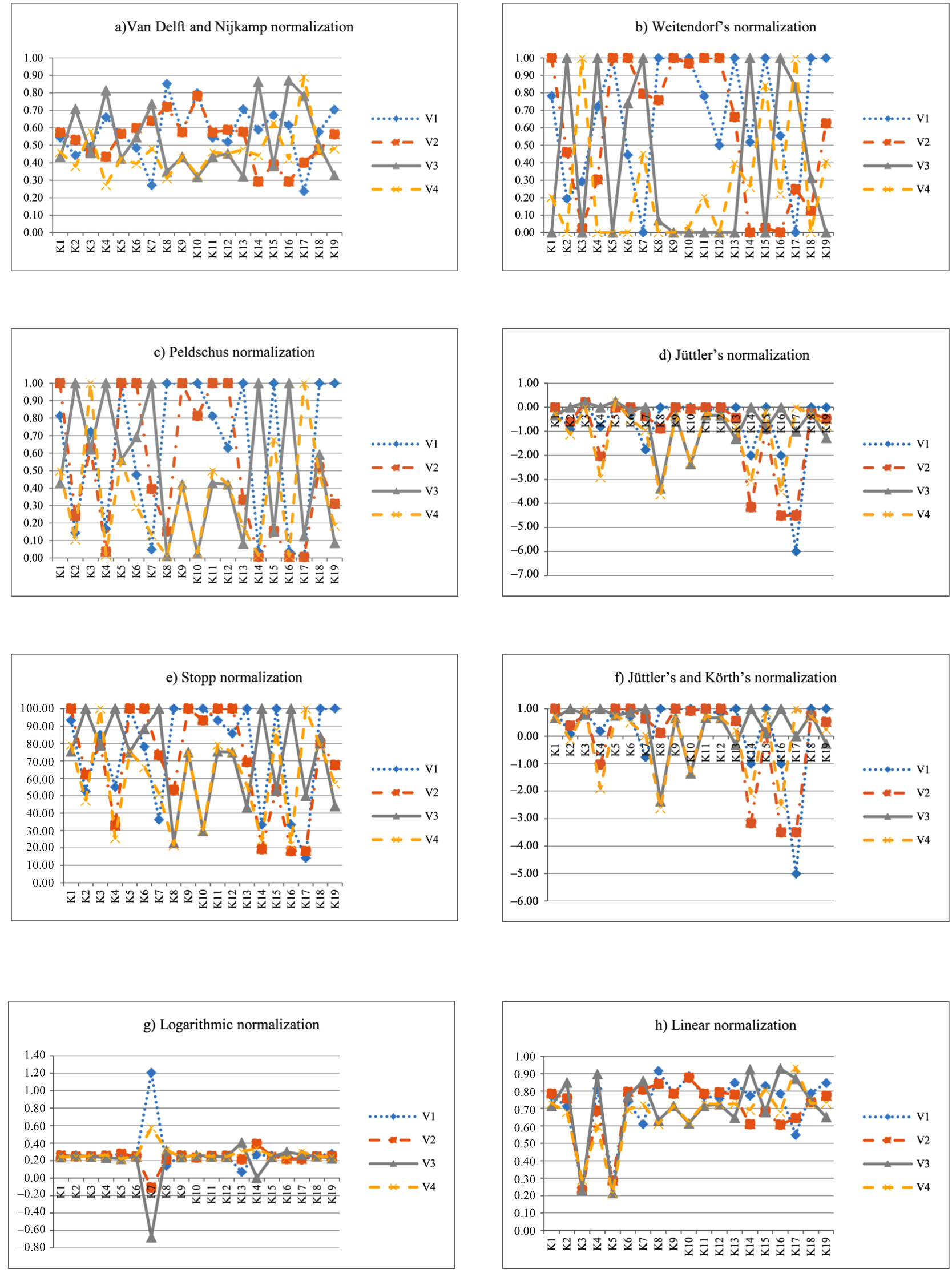

Fig. $2(\mathrm{a}-\mathrm{h})$. Criteria normalization according to the analysed methods 

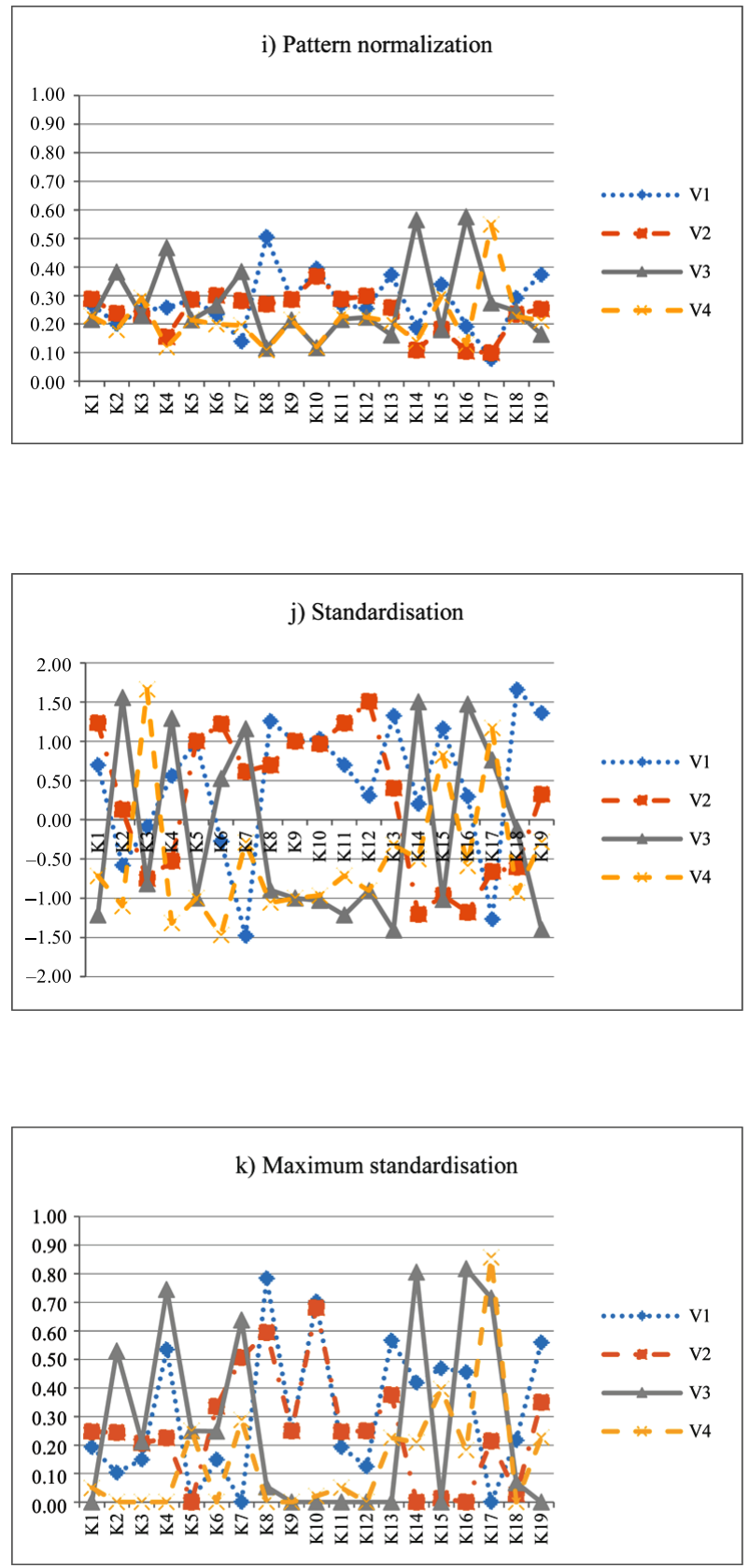

Fig. 2 (i-k). Criteria normalization according to the analysed methods

The third group includes methods (by Jüttler, Jüttler and Körth, the logarithmic method, standardization) for which some criteria have the value from outside the [0-1] range and can be positive as well as negative.

The values of criteria after normalization (outside the $0-1$ range), determined according to methods from the second and the third group, can have a significant influence on the choice of the variant assessment method.

\subsection{Assessment methods and variant rankings}

In order to determine the ranking of variants, calculations were conducted using eleven criteria normalization methods and six variant assessment methods presented in point 4 . In the case of methods by Wald, Savage, Hurwicz and Laplace the analysis was conducted without taking the criteria weights into account. However, criteria weights were used in methods by Bayes and HodgesLehmann. The approach of equal values was used for the selected criteria weights $(0.25$ - in each criteria group). The sub-criteria had an equal share within the individual criteria groups (Table 3). A visual analysis of the variant assessment methods for the selection of the bypass alignment of the town of Księżyno is presented in Figure 3. The variant ranking according to the analysed methods, without taking criteria weights into account, is presented in Table 4, while Table 5 shows the same ranking, however the criteria weights are taken into account this time. The notation shown in Tables 4 and 5: $V 3 \succ V 4 \succ V 2 \succ V 1$ means that the $V 3$ variant is better than the $V 4$ variant, the $V 4$ variant is better than the $V 2$ variant and the $V 2$ variant is better than the $V 1$ variant.

Table 3. Distribution of weights according to the equal weights approach

\begin{tabular}{|c|c|c|}
\hline No. & Criteria & Weights \\
\hline \multicolumn{3}{|c|}{ TRANSPORT 0.25} \\
\hline$K 1$ & Length of road & $1 / 20$ \\
\hline$K 2$ & Tortuosity of road & $1 / 20$ \\
\hline$K 3$ & Transport activity & $1 / 20$ \\
\hline$K 4$ & Occupation of housing terrain & $1 / 20$ \\
\hline$K 5$ & Availability - number of crossings & $1 / 20$ \\
\hline \multicolumn{3}{|c|}{ ENVIRONMENTAL 0.25} \\
\hline K6 & Occupation of new terrain & $1 / 20$ \\
\hline$K 7$ & Length of road through forest areas & $1 / 20$ \\
\hline$K 8$ & $\begin{array}{l}\text { Length of collision with amphibian } \\
\text { migratory corridors }\end{array}$ & $1 / 20$ \\
\hline$K 9$ & $\begin{array}{l}\text { Influence on surface waters - collision } \\
\text { with watercourses }\end{array}$ & $1 / 20$ \\
\hline$K 10$ & Collision with valuable nature areas & $1 / 20$ \\
\hline \multicolumn{3}{|c|}{ ECONOMIC 0.25} \\
\hline$K 11$ & Construction cost & $1 / 16$ \\
\hline$K 12$ & $\begin{array}{l}\text { Number of engineering structures - } \\
\text { passages for animals and amphibians }\end{array}$ & $1 / 16$ \\
\hline$K 13$ & Cost of environment protection equipment & $1 / 16$ \\
\hline$K 14$ & Cost of buying out terrain and buildings & $1 / 16$ \\
\hline \multicolumn{3}{|c|}{ SOCIAL 0.25} \\
\hline$K 15$ & $\begin{array}{l}\text { Number of housing buildings within } \\
\text { a } 0,1 \mathrm{~km} \text { distance from road axis }\end{array}$ & $1 / 20$ \\
\hline$K 16$ & $\begin{array}{l}\text { Number of housing buildings to be } \\
\text { demolished }\end{array}$ & $1 / 20$ \\
\hline$K 17$ & $\begin{array}{l}\text { Number of agricultural buildings to be } \\
\text { demolished }\end{array}$ & $1 / 20$ \\
\hline$K 18$ & Number of plots to be expropriated & $1 / 20$ \\
\hline$K 19$ & Length of noise barriers & $1 / 20$ \\
\hline
\end{tabular}



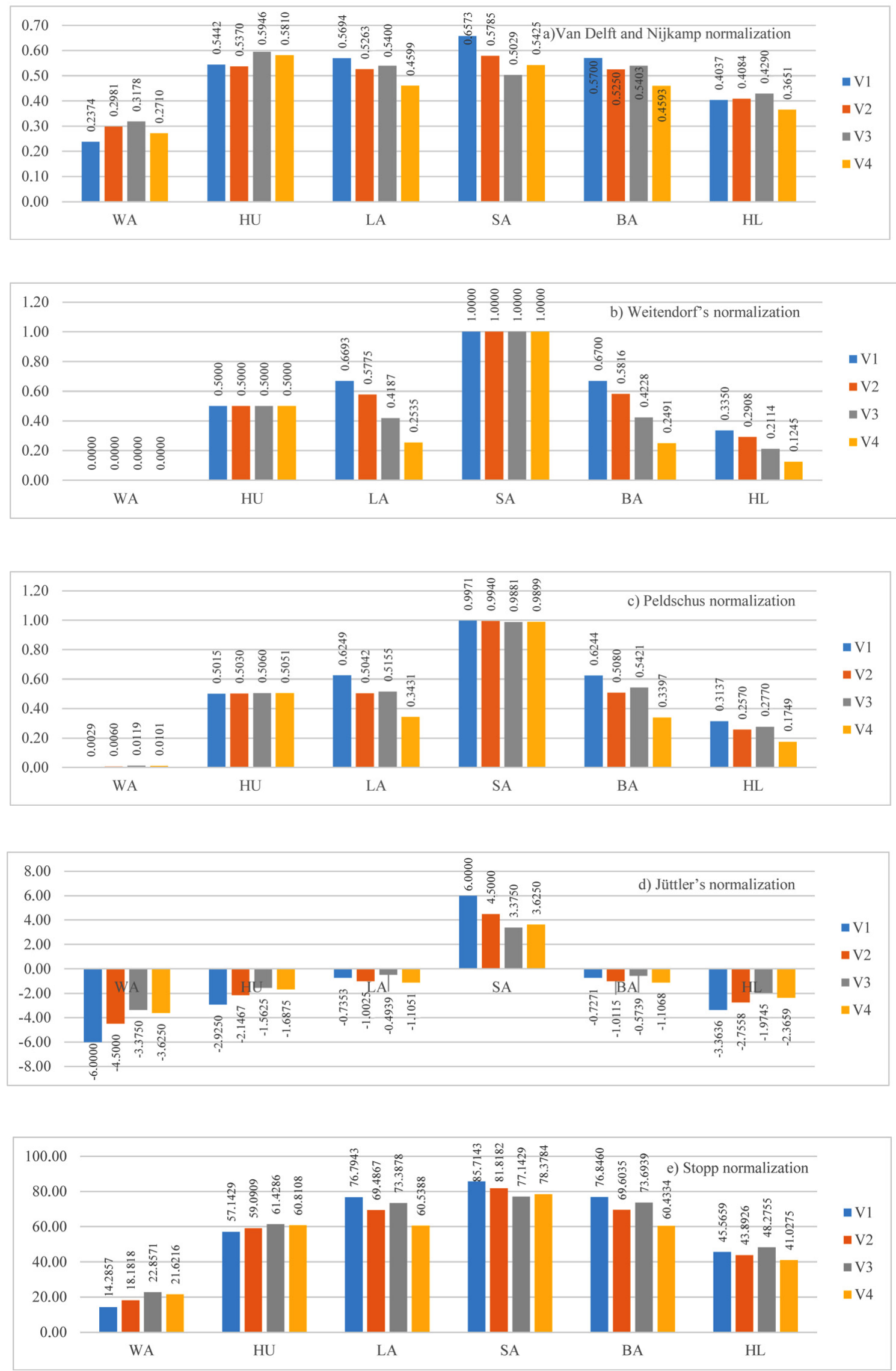

Fig. 3 (a-e). Variant ranking according to the analysed assessment methods 

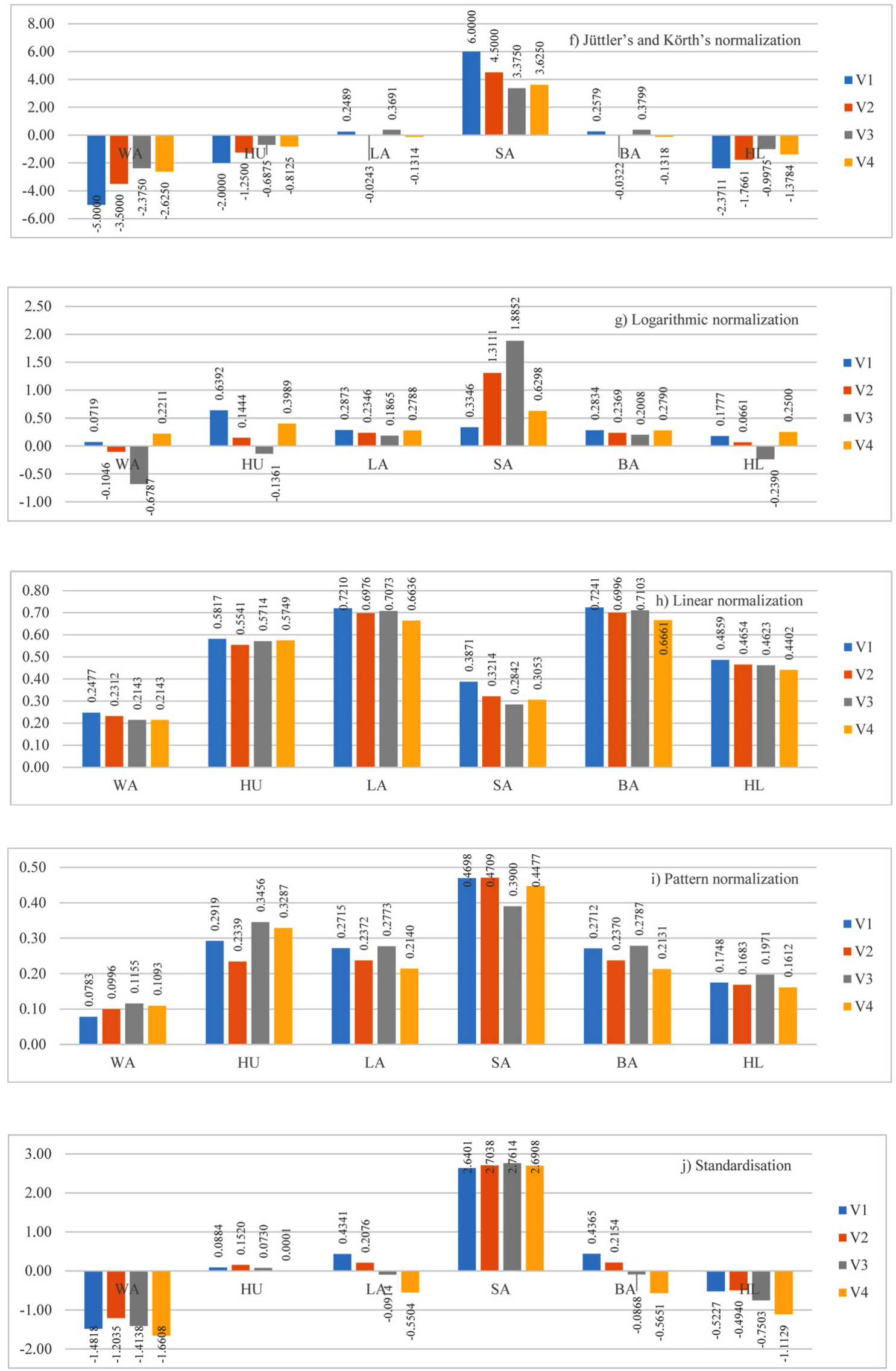

Fig. 3 (f-j). Variant ranking according to the analysed assessment methods 


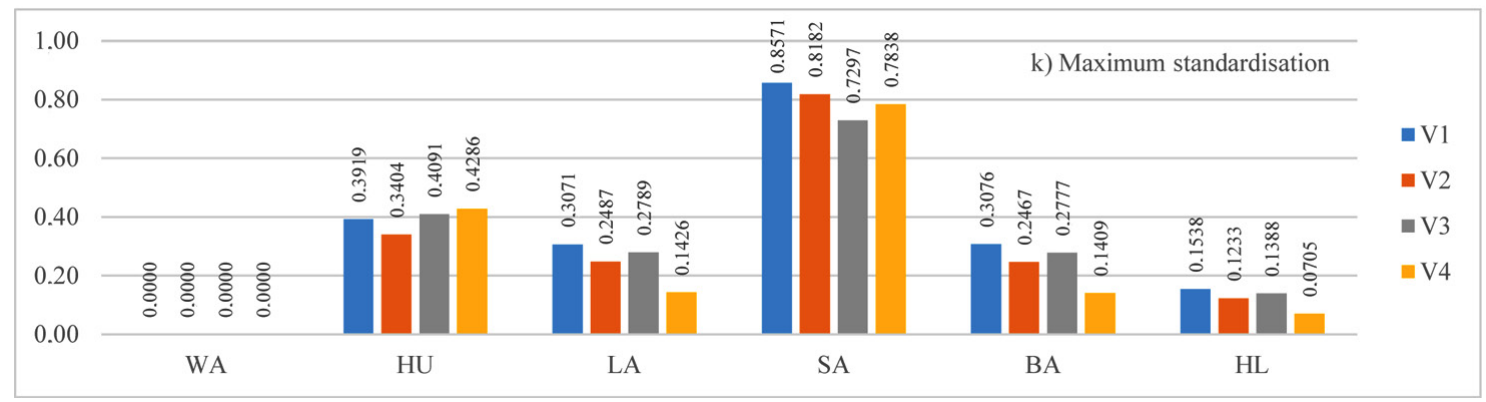

Fig. 3 (k). Variant ranking according to the analysed assessment methods

Table 4. Variant ranking according to the analysed methods without taking criteria weights into account

\begin{tabular}{|c|c|c|c|c|}
\hline \multirow{2}{*}{ Normalization method } & \multicolumn{4}{|c|}{ Variant ranking method } \\
\hline & Wald's & Savage & Hurwicz's* & Laplace's \\
\hline Van Delft and Nijkamp & $V 3 \succ V 2 \succ V 4 \succ V 1$ & $V 3 \succ V 4 \succ V 2 \succ V 1$ & $V 3 \succ V 4 \succ V 1 \succ V 2$ & $V 1 \succ V 3 \succ V 2 \succ V 4$ \\
\hline Weitendorf & $V 1=V 2=V 3=V 4$ & $V 1=V 2=V 3=V 4$ & $V 1=V 2=V 3=V 4$ & $V 1 \succ V 2 \succ V 3 \succ V 4$ \\
\hline Peldschus & $V 3 \succ V 4 \succ V 2 \succ V 1$ & $V 3 \succ V 4 \succ V 2 \succ V 1$ & $V 3 \succ V 4 \succ V 2 \succ V 1$ & $V 1 \succ V 3 \succ V 2 \succ V 4$ \\
\hline Jüttler & $V 3 \succ V 4 \succ V 2 \succ V 1$ & $V 3 \succ V 4 \succ V 2 \succ V 1$ & $V 3 \succ V 4 \succ V 2 \succ V 1$ & $V 3 \succ V 1 \succ V 2 \succ V 4$ \\
\hline Stopp & $V 3 \succ V 4 \succ V 2 \succ V 1$ & $V 3 \succ V 4 \succ V 2 \succ V 1$ & $V 3 \succ V 4 \succ V 2 \succ V 1$ & $V 1 \succ V 3 \succ V 2 \succ V 4$ \\
\hline Jüttler and Körth & $V 3 \succ V 4 \succ V 2 \succ V 1$ & $V 3 \succ V 4 \succ V 2 \succ V 1$ & $V 3 \succ V 4 \succ V 2 \succ V 1$ & $V 3 \succ V 1 \succ V 2 \succ V 4$ \\
\hline Logarithmic & $V 4 \succ V 1 \succ V 2 \succ V 3$ & $V 1 \succ V 4 \succ V 2 \succ V 3$ & $V 1 \succ V 4 \succ V 2 \succ V 3$ & $V 1 \succ V 4 \succ V 2 \succ V 3$ \\
\hline Linear normalization & $V 1 \succ V 2 \succ V 3 \succ V 4$ & $V 3 \succ V 4 \succ V 2 \succ V 1$ & $V 1 \succ V 4 \succ V 3 \succ V 2$ & $V 1 \succ V 3 \succ V 2 \succ V 4$ \\
\hline Pattern & $V 3 \succ V 4 \succ V 2 \succ V 1$ & $V 3 \succ V 4 \succ V 1 \succ V 2$ & $V 3 \succ V 4 \succ V 1 \succ V 2$ & $V 3 \succ V 2 \succ V 1 \succ V 4$ \\
\hline Standardisation & $V 4 \succ V 2 \succ V 3 \succ V 1$ & $V 1 \succ V 4 \succ V 2 \succ V 3$ & $V 2 \succ V 1 \succ V 3 \succ V 4$ & $V 1 \succ V 2 \succ V 3 \succ V 4$ \\
\hline Maximum standardisation & $V 1=V 2=V 3=V 4$ & $V 3 \succ V 4 \succ V 2 \succ V 1$ & $V 3 \succ V 4 \succ V 1 \succ V 2$ & $V 3 \succ V 1 \succ V 2 \succ V 4$ \\
\hline
\end{tabular}

Table 5. Variant ranking according to the analysed methods taking criteria weights into account

\begin{tabular}{|c|c|c|}
\hline \multirow{2}{*}{$\begin{array}{l}\text { Normalization } \\
\text { method }\end{array}$} & \multicolumn{2}{|c|}{ Variant ranking methods } \\
\hline & Bayes's & Hodges-Lehmann* \\
\hline $\begin{array}{l}\text { Van Delft and } \\
\text { Nijkamp }\end{array}$ & $V 1 \succ V 3 \succ V 2 \succ V 4$ & $V 3 \succ V 2 \succ V 1 \succ V 4$ \\
\hline Weitendorf & $V 1 \succ V 2 \succ V 3 \succ V 4$ & $V 1 \succ V 2 \succ V 3 \succ V 4$ \\
\hline Peldschus & $V 1 \succ V 3 \succ V 2 \succ V 4$ & $V 1 \succ V 3 \succ V 2 \succ V 4$ \\
\hline Jüttler & $V 3 \succ V 1 \succ V 2 \succ V 4$ & $V 3 \succ V 4 \succ V 2 \succ V 1$ \\
\hline Stopp & $V 1 \succ V 3 \succ V 2 \succ V 4$ & $V 3 \succ V 1 \succ V 2 \succ V 4$ \\
\hline Jüttler and Körth & $V 3 \succ V 1 \succ V 2 \succ V 4$ & $V 3 \succ V 4 \succ V 2 \succ V 1$ \\
\hline Logarithmic & $V 1 \succ V 4 \succ V 2 \succ V 3$ & $V 4 \succ V 1 \succ V 2 \succ V 3$ \\
\hline $\begin{array}{l}\text { Linear } \\
\text { normalization }\end{array}$ & $V 1 \succ V 3 \succ V 2 \succ V 4$ & $V 1 \succ V 2 \succ V 3 \succ V 4$ \\
\hline Pattern & $V 3 \succ V 2 \succ V 1 \succ V 4$ & $V 3 \succ V 1 \succ V 2 \succ V 4$ \\
\hline Standardisation & $V 1 \succ V 2 \succ V 3 \succ V 4$ & $V 2 \succ V 1 \succ V 3 \succ V 4$ \\
\hline $\begin{array}{l}\text { Maximum } \\
\text { standardisation }\end{array}$ & $V 1 \succ V 3 \succ V 2 \succ V 4$ & $V 1 \succ V 3 \succ V 2 \succ V 4$ \\
\hline
\end{tabular}

The data presented in Figure 3 have confirmed that the usage of some criteria normalization methods in the discussed methods of variant assessment is not possible. This is an issue for the normalization method by Weitendorf, while using the assessment methods by Wald, Savage and Hurwicz. This is a result of the criteria values, which reach " 0 "and "1" after normalization. Such situation occurs in the case of normalization using the maximum standardization method and the variant assessment method by Wald.

Normalization methods which in point 5.2 were included in the first group, in an analysis without taking criteria weights into account (Table 4) pointed to the $V 3$ variant as the most beneficial solution according to assessment methods by Wald, Savage and Hurwicz, whereas they pointed to the $V 1$ variant as the most beneficial according to the method by Laplace. In an analysis of the variant ranking (Table 5) while taking criteria weights into account, the $V 1$ variant was selected as the best solution according to the method by Bayes, whereas the $V 3$ variant was selected according to the method by HodgesLehmann. 
Table 6. A summary of the most beneficial variants

\begin{tabular}{|c|c|c|c|c|c|c|c|c|c|c|}
\hline \multirow{2}{*}{ Normalization method } & \multicolumn{6}{|c|}{ Methods of variants assessment } & \multicolumn{4}{|c|}{ Variants } \\
\hline & WA & SA & $\mathrm{HU}$ & LA & $\mathrm{BA}$ & $\mathrm{HL}$ & V1 & $\mathrm{V} 2$ & V3 & V4 \\
\hline Van Delft and Nijkamp & $V 3$ & $V 3$ & $V 3$ & $V 1$ & $V 1$ & $V 3$ & 2 & - & 4 & - \\
\hline Weitendorf & - & - & - & $V 1$ & $V 1$ & $V 1$ & 3 & - & - & - \\
\hline Peldschus & $V 3$ & $V 3$ & $V 3$ & $V 1$ & $V 1$ & $V 1$ & 3 & - & 3 & - \\
\hline Jüttler & $V 3$ & $V 3$ & $V 3$ & $V 3$ & $V 3$ & $V 3$ & - & - & 6 & - \\
\hline Stopp & $V 3$ & $V 3$ & $V 3$ & $V 1$ & $V 1$ & $V 3$ & 2 & - & 4 & - \\
\hline Jüttler and Körth & $V 3$ & $V 3$ & $V 3$ & $V 3$ & $V 3$ & $V 3$ & - & - & 6 & - \\
\hline Logarithmic & $V 4$ & $V 1$ & $V 1$ & $V 1$ & $V 1$ & $V 4$ & 4 & - & - & 2 \\
\hline Linear normalization & $V 1$ & $V 3$ & $V 1$ & $V 1$ & $V 1$ & $V 1$ & 5 & - & 1 & - \\
\hline Pattern & $V 3$ & $V 3$ & $V 3$ & $V 3$ & $V 3$ & $V 3$ & - & - & 6 & - \\
\hline Standardisation & $V 4$ & $V 1$ & $V 2$ & $V 1$ & $V 1$ & $V 2$ & 3 & 2 & - & 1 \\
\hline Maximum standardisation & - & $V 3$ & $V 4$ & $V 3$ & $V 1$ & $V 1$ & 2 & - & 2 & 1 \\
\hline Total & & & & & & & 24 & 2 & 32 & 4 \\
\hline
\end{tabular}

The methods of normalization included in the second group in the analysis without taking criteria weights into account (Table 4) pointed to the $V 3$ variant as the most beneficial one according to assessment methods by Wald, Savage and Hurwicz, whereas in the case of the assessment method by Laplace - to the $V 1$ variant. Analysing the ranking variant (Table 5) while taking criteria weights into account, the best solution was the $V 1$ variant according to assessment methods by Bayes and HodgesLehmann.

In the case of using normalization methods which lead to the obtaining of positive and negative values (in point 5.2 included in group 3), the selection of the best variant is not possible according to assessment methods by Wald, Savage and Laplace. However in the case of the assessment method by Hurwicz, the $V 3$ variant is the best solution. A similar situation occurs in the case of an analysis with criteria weights being taken into account it is not possible to select the best variant using assessment methods by Bayes, whereas the Hodges-Lehmann method points to the $V 3$ variant as the most beneficial.

When not taking criteria weights into account (Table 4), the variant rankings are in agreement according to assessment methods by Wald, Savage, Hurwicz and Laplace, when using the normalization methods by Weitendorf, Jüttler, Jüttler and Körth and Pattern. These methods pointed to the $V 1$ or $V 3$ variants as the most beneficial.

While taking the criteria weights into account (Table 5), the variant rankings are in agreement according to assessment methods by Bayes and Hodges-Lehmann, when using the normalization methods by Weitendorf, Peldschus Jüttler, Jüttler and Körth, linear standardisation, Pattern and maximum standardisation. These methods pointed to the $V 1$ or $V 3$ variants as the most beneficial.

A full agreement of the variant ranking with and without criteria weights was obtained for six assessment methods while using the normalization method by Weitendorf (the $V 1$ variant as the best one), Jüttler, Jüttler and Körth and Pattern (the $V 3$ variant as the best one) (Tables 4 and 5).

In summary, it can be stated that the conducted analysis of the results obtained with six variant assessment methods, using eleven criteria normalization methods, did not present a unanimous answer to the issue of selecting the most beneficial road alignment variant. However, with the intention of forming a conclusion from the conducted analysis, Table 6 shows a cumulative breakdown of the most beneficial variants determined using the analysed methods of criteria normalization and variant assessment methods. The data in the table show that the $V 1$ and $V 3$ variants are decidedly more beneficial options than the $V 2$ and $V 4$ variants, with the $V 3$ variant being more beneficial than the $V 1$ variant.

It needs to be mentioned, that in the case of methods by Bayes and Hodges-Lehmann, an approach with identical weights and an optimism coefficient of $\lambda=0.5$ was used. When using different weight values or $\lambda$ coefficients, after their initial determination (e.g. through surveys) the end result could vary. This signals the need for further, more detailed analyses of the choice of both the criteria normalization methods as well as the variant assessment methods. One such solution could be the suggested algorithm presented in the work by Migilinskas and Ustinovichius (2007).

\section{Conclusions}

The multicriteria analysis is very useful for determining the most beneficial solution when designing bypasses of towns. The choice of the road alignment variant requires taking into account criteria of various significance. These criteria, are usually: transport criteria, economical criteria, environmental criteria and social criteria. The values of these criteria are expressed in various units and they need to be normalized. The most often used normalization methods are: normalization by Van Delft and Nijkamp, Weitendorf, Peldschus, Jüttler and Körth, linear normalization. The determined road alignment variants, 
based on the normalized criteria, are then assessed using methods by: Wald, Laplace and Bayes.

In the analysed road alignment choice for the bypass of the town of Księżyno, which is a section of the Regional Road 678, the calculations conducted using eleven criteria normalization methods and six variant assessment methods, did not yield a unified result. Depending on the normalization method and the variant assessment method, the most beneficial variant was often the $V 3$ variant, which had a slight advantage over the $V 1$ variant. Only in singular cases, were the $V 2$ and $V 4$ variants pointed to as being the best ones. Based on the obtained results, however, it cannot be concluded that the $V 3$ variant is decidedly the most beneficial one, as the analysis used weights with identical values (without taking into account e.g. expert opinions), and the $\lambda$ coefficient was always an even 0.5 .

The analysis of the criteria normalization methods enabled to determine, that some of those methods (e.g. Weitendorf's, maximum standardisation) cannot be used with some variant assessment methods (Wald's, Savage's, Hurwicz's) due to it being impossible to determine a variant ranking. The reason for this are criteria values " 0 " and "1" after normalization.

In the case of criteria normalization methods such as: Jüttler's, Jüttler and Körth's, logarithmic and standardisation, negative values are obtained, which causes the elimination of these methods in the case of variant assessment methods requiring normalized values to be greater than 0 .

The most appropriate criteria normalization methods seem to be methods by: Van Delft and Nijkamp, linear normalization and Pattern. They allow the comparison of any number of criteria, and the normalized values do not contain negative values, zeroes and ones.

When selecting the variant assessment method, it needs to be mentioned that in the case of the methods by Bayes and Hodges-Lehmann criteria weights and optimism coefficients $\lambda$ can be of significance. Their values should be selected in relations to the analysed variants, location of the road or the importance of the individual criteria.

\section{References}

Barzilai, J.; Golany, B. 1994. AHP rank reversal, normalization and aggregation rules, Information Systems and Operational Research 32: 57-64. https://doi.org/10.1080/03155 986.1994.11732238

Brans, J. P.; Vincke, P. H. 1985. A preference ranking organisation method (The PROMETHEE method for multiple criteria decision-making), Management Science 3(6): 647656. https://doi.org/10.1287/mnsc.31.6.647

Brauers, W. K. M.; Zavadskas, E. K.; Peldschus, F.; Turskis, Z. 2008. Multi-objective decision-making for road design, Transport 23(3): 183-193. https://doi.org/10.3846/16484142.2008.23.183-193

Brauers, W. K.; Zavadskas, E. K. 2006. The MOORA method and its application to privatization in a transition economy, Control and Cybernetics 35(2): 443-468.
Celen, A. 2014. Comparative analysis of normalization procedures in TOPSIS method: with an application to Turkish deposit banking market, Informatica 25(2): 185-208. https://doi.org/10.15388/Informatica.2014.10

Chakraborty, S.; Yeh, C. H. 2007. A simulation based comparative study of normalization procedures in multiattribute decision making, in Proceedings of the $6^{\text {th }}$ WSEAS International Conference on Artificial Intelligence, Knowledge Engineering and Data Bases, 2007, Corfu Island, Greece, 6: 102-109.

Chatterjee, P.; Chakraborty, S. 2014. Investigating the effect of normalization norms in flexible manufacturing system selection using multi-criteria decision-making methods, Journal of Engineering Science and Technology Review 7(3): 141-150.

De Silva, H.; Tatam, C. H. 1996. An empirical procedure for enhancing the impact of road investments, Transport Policy 3(4): 210-221. https://doi.org/10.1016/S0967070X(96)00019-4

De Luca, M.; Dell'Acqua, G.; Lamberti, R. 2012. High-speed rail track design using GIS and multi-criteria analysis, Procedia: Social and Behavioral Sciences 54: 608-617. https://doi.org/10.1016/j.sbspro.2012.09.778

Gardziejczyk, W.; Zabicki, P. 2014. The influence of the scenario and assessment method on the choice of road alignment variants, Transport Policy 36: 294-305. https://doi.org/10.1016/j.tranpol.2014.10.001

Garcia-Cascales, M. S.; Lamata, M. T. 2012. On rank reversal and TOPSIS method, Mathematical Computer Modelling 56: 123-32. https://doi.org/10.1016/j.mcm.2011.12.022

Geneletti, D. 2005. Multicriteria analysis to compare the impact of alternative road corridors: a case study in northern Italy, Impact Assessment and Project Appraisal 23(2): 135-146. https://doi.org/10.3152/147154605781765661

Haghighat, F. 2011. Application of a multi-criteria approach to road safety evaluation in the Bushehr province, Iran, Promet - Traffic \& Transportations 23(5): 341-352.

Hwang, C. L.; Yoon, K. 1981. Multiple attribute decision making methods and applications. Springer, Berlin Heidelberg. https://doi.org/10.1007/978-3-642-48318-9

Jahan, A.; Edwards, K. L. 2015. A state-of-the-art survey on the influence of normalization techniques in ranking: improving the materials selection process in engineering design, Materials \& Design 65: 335-342.

https://doi.org/10.1016/j.matdes.2014.09.022

Jakimavicus, M.; Burinskiene, M. 2009. Assessment of Vilnius city development scenarios based on transport system modelling and multicriteria analysis, Journal of Civil Engineering and Management 15(4): 361-368. https://doi.org/10.3846/1392-3730.2009.15.361-368

Kalamaras, G. S.; Brino, L.; Carrieri, G.; Pline, C.; Grasso, P. 2000. Application of multicriteria analysis to select the best highway alignment, Tunneling and Underground Space Technology 15(4): 415-420. https://doi.org/10.1016/ S0886-7798(01)00010-4

Keeney, R.; Raiffa, H. 1976. Decisions with multiple objectives: preferences and value tradeoffs. New York: Wiley.

MacCrimon, K. R. 1968. Decision making among multiple-attribute alternatives: a survey and consolidated approach. RAND Memorandum, RM-4823-ARPA.

Migilinskas, D.; Ustinovichius L. 2007. Normalisation in the selection of construction alternatives, International Journal of Management and Decision Making 8(5/6): 623-272. https://doi.org/10.1504/IJMDM.2007.013422

Milani, A. S.; Shanian, A.; Madiolat, R.; Nemes, J. A. 2005. The effect of normalization norms in multiple attribute decision making models: a case study in gear material selection, Structural and Multidisciplinary Optimization 29(4): 312-318. https://doi.org/10.1007/s00158-004-0473-1 
Opricovic, S.; Tzeng, G. H. 2004. Compromise solution by MCDM methods: a comparative analysis of VIKOR and TOPSIS, European Journal of Operational Research 156: 445-455. https://doi.org/10.1016/S03772217(03)00020-1

Peldschus, F. 2009. The analysis of the quality of the results obtained with the methods of multi-criteria decisions, Technological and Economic Development of Economy 15(4): 580-592. https://doi.org/10.3846/1392-8619.2009.15.580592

Roy, B. 1985. Méthodologie multicritère d'aide à la decision. Economica, Paris.

Saaty, T. L. 1980. The analytic hierarchy process. New York: McGraw-Hill.

Szwabowski, J.; Deszcz, J. 2001. Metody wielokryterialnej analizy porównawczej [Methods of multi-criteria analysis]. Gliwice: Wydawnictwo Politechniki Śląskiej. 27 p.

Turskis, Z.; Zavadskas, E. K.; Peldschus, F. 2009. Multi-criteria optimization system for decision making in construction design and management, Inzinerine ekonomika-Engineering Economics (1): 7-17.
Yelda, S.; Shrestha, R. M. 2003. Multi-criteria approach for the selection of alternative options for environmentally sustainable transport system in Delhi, Transportation Research Part A 37: 717-729. https://doi.org/10.1016/ S0965-8564(03)00027-2

Zavadskas, E. K.; Ustinovichius, L.; Peldschus, F. 2003. Development of software for multiple criteria evaluation, Informatica 14(2): 259-272.

Zavadskas, E. K.; Kaklauskas, A.; Peldschus, F.; Turskis, Z. 2007. Multi-attribute assessment of road design solutions by using the Copras method, Baltic Journal of Road \& Bridge Engineering 2(4): 195-203.

Zavadskas, E. K.; Turskis, Z. 2008. A new logarithmic normalization method in games theory, Informatica 19(2): 303-314.

Zavadskas, E. K.; Turskis, Z.; Peldschus, F. 2008. Multi-criteria optimization software Levi-4.0 a tool to support design and management in construction, in The $25^{\text {th }}$ International Symposium on Automation and Robotics in Construction (ISARC 2008), 26-29 June 2008, Vilnius, Lithuania, 731-736.

Władysław GARDZIEJCZYK. Associate Professor, Faculty of Civil and Environmental Engineering, Bialystok University of Technology, Poland. His research interests include road design problems and issues related to research tire/road noise.

Piotr ŻABICKI. PhD student, Faculty of Civil and Environmental Engineering, Bialystok University of Technology, Poland. His research interest include multicriteria analysis in the design of roads. 